\title{
Interleukin-35 sensitizes monocytes from patients with asthma to glucocorticoid therapy by regulating p38 MAPK
}

\author{
LEI QIAN $^{1 *}$, DONGHUI XU ${ }^{2 *}$, FANGSU XUE ${ }^{3}$, MING LI $^{1}$, XUSHAN WANG $^{4}$ and GUANGLIANG LIU ${ }^{2}$ \\ Departments of ${ }^{1}$ Laboratory Medicine, ${ }^{2}$ Pediatrics and ${ }^{3}$ Respiration, Binhai County People's Hospital, \\ Yancheng, Jiangsu 224500; ${ }^{4}$ Department of Laboratory Medicine, Guanyun County People's Hospital, \\ Lianyungang, Jiangsu 222200, P.R. China
}

Received December 10, 2018; Accepted January 31, 2020

DOI: $10.3892 /$ etm.2020.8586

\begin{abstract}
The activation of monocytes and macrophages is associated with steroid-resistant (SR) asthma. Interleukin-35 (IL-35) is an important anti-inflammatory cytokine, but its regulatory effects on monocytes in patients with SR asthma is not fully understood. Based on clinical response to oral prednisolone, 34 patients with steroid-sensitive (SS) asthma and 20 patients with SR asthma were enrolled in the present study. Serum IL-35 levels were analyzed using the Luminex 200 platform. Monocytes from patients with asthma were pretreated with IL-35 followed by dexamethasone (DEX) and lipopolysaccharide (LPS), then corticosteroid sensitivity was evaluated according to the half-maximal inhibitory concentration of DEX with respect to LPS-induced IL-6 maximal production in monocytes $\left(\mathrm{DEX}-\mathrm{IC}_{50}\right)$. The percentage of maximal inhibition of IL- 6 by DEX was presented as $\mathrm{E}_{\max }$. Phosphorylated-P38 mitogen activated kinase (p-p38 MAPK) and mitogen-activated protein kinase phosphatase-1 (MKP-1) were examined by flow cytometry and reverse transcription-quantitative PCR analysis, respectively. Glucocorticoid receptor $(\mathrm{GR})$ binding to the glucocorticoid response element (GRE) was assessed by chromatin immunoprecipitation. Compared with patients with SS asthma, patients with SR asthma had lower IL-35 expression levels $(\mathrm{P}<0.05)$. Correlation
\end{abstract}

Correspondence to: Professor Guangliang Liu, Department of Pediatrics, Binhai County People's Hospital, 248 Fudongzhong Road, Dongkan, Yancheng, Jiangsu 224500, P.R. China

E-mail: bhxrmyc@163.com

*Contributed equally

Abbreviations: IL, interleukin; DEX, dexamethasone; SR, steroid-resistant; SS, steroid-sensitive; MKP-1, mitogen-activated protein kinase phosphatase-1; GR, glucocorticoid receptor; GRE, glucocorticoid response element; GCs, glucocorticoids; AHR, airway hyperresponsiveness; p-p38 MAPK, phosphorylated P38 mitogen activated kinases; PBMCs, peripheral blood mononuclear cells; EBI3, Epstein-Barr virus-induced gene 3

Key words: asthma, steroid resistance, DEX, IL-35 analysis results demonstrated that the expression levels of IL-35 showed a weak negative correlation with $\log \mathrm{DEX}-\mathrm{IC}_{50}$ $(\mathrm{r}=-0.351 ; \mathrm{P}<0.01)$ and a moderate positive correlation with $\mathrm{E}_{\max }$ value $(\mathrm{r}=0.4501 ; \mathrm{P}<0.01)$ in all patients with asthma. Moreover, IL-35 enhanced DEX-suppressed IL-6 production and the DEX-induced upregulation of the MKP-1 mRNA expression level in monocytes from both patient groups $(\mathrm{P}<0.01)$. In addition, IL-35 inhibited p-p38 MAPK expression in monocytes, and these effects were mediated via an increase in DEX-induced GR binding to GRE. Therefore, IL-35 may be involved in the corticosteroid enhancing effects in monocytes of patients with SR and SS asthma, suggesting potential benefits of IL-35 supplementation in asthmatics with DEX.

\section{Introduction}

Despite the demonstrable benefit of inhaled glucocorticoids (GCs) for improving asthma symptoms and lung function in patients with asthma, referred to as steroid-sensitive (SS) asthma, it is estimated that $\leq 5 \%$ of asthma cases are relatively insensitive to steroid therapy (1). Aside from Th17-induced airway inflammation, it is apparent that activation of monocytes and macrophages is associated with steroid-resistant (SR) asthma (2,3). Macrophage-induced airway inflammation in mice is associated with SR airway inflammation and airway hyperresponsiveness (AHR) (4). Mechanistically, monocytes contribute to the amplification of inflammation in an asthma mouse model, including generation of cytokines and acceleration of the T helper cell 2 (Th2)-mediated immune response via their differentiation into dendritic cells and inflammatory macrophages (5-7). Clinical studies have also revealed that monocytes from patients with SR asthma show functional activation compared with those from patients with SS asthma (8). Thus, modulation of monocyte activation may be an effective therapeutic approach for SR asthma.

GCs exert a wide range of anti-inflammatory effects on monocytes after binding to their glucocorticoid receptors (GR), which translocate into the nucleus from cytoplasm (9). GRs then bind to glucocorticoid response elements (GRE) and regulate the transcription of related genes, including mitogen-activated kinase phosphatase (MKP-1) (10). MKP-1, a phosphatase, selectively inactivates phosphorylated-p38 mitogen activated kinases (p-p38 MAPK), thus suppressing 
the production of pro-inflammatory cytokines (11). It has been reported that p38 MAPK pathway activation in peripheral blood mononuclear cells (PBMCs) is significantly increased in patients with SR asthma compared with patients with SS asthma (8). In addition, previous studies showed that inhibition of $\mathrm{p} 38$ MAPK pathway activation using vitamin D or p-p38 MAPK inhibitor significantly enhanced dexamethasone (DEX)-induced inhibition of cellular responsiveness to GCs in patients with SR asthma $(3,12,13)$. Therefore, targeting the GRE-based signaling pathway may be a novel therapeutic strategy for SR asthma.

Interleukin (IL)-35 is an important anti-inflammatory cytokine formed by IL-12 $\alpha$ and Epstein-Barr virus-induced gene 3 (EBI3), and underpins the pathogenesis of asthma (14). In a mouse model, administration of recombinant IL-35 (AdIL-35) reversed IL-17-dependent AHR and suppressed the severity of airway inflammation $(15,16)$. Histological analysis shows that AdIL-35 reduces the number of pro-inflammatory cells and levels of pro-inflammatory cytokines, including IL-17, IL-4 and IL-5, in bronchoalveolar lavage fluid $(17,18)$. Interleukin-35-induced regulatory T cells (iTr35) are known to suppress the proliferation of Th17 cells and to inhibit the inflammatory response of immune cells $(16,19)$. However, it is still unknown whether IL-35 can efficiently enhance the inhibitory effect of DEX on monocytes in patients with SR asthma.

Therefore, the present study investigated the percentage of iTr35 cells and the expression levels of serum IL-35 in peripheral blood from patients with SR or SS asthma. In addition, the effects of IL-35 on cellular responses to glucocorticoids in vitro were examined in the monocytes of these patients. Furthermore, the present study analyzed the effects of IL-35 on the induction of mitogen-activated protein kinase phosphatase-1 (MKP-1) expression and the recruitment of GR to the GRE in monocytes. It was found that decreased IL-35 expression levels in peripheral blood from patients with SR asthma were involved in the corticosteroid insensitivity of monocytes, suggesting potential benefits of IL-35 supplementation in patients with asthma with DEX.

\section{Materials and methods}

Study population. The present study was carried out under ethical approval from the Ethics Committee of Binhai Hospital (approval no. 2017/05). After detailed explanation, informed consent was provided by all patients. The sample size was determined using a calculation for two-samples t-test and it was expected that a difference of $0.2 \mathrm{ng} / \mathrm{ml}$ would be detected in serum IL-35 between patients with SR or SS asthma. To have a study with a power of $1-\beta=0.90$ and a statistical difference of $\mathrm{P}<0.05$, a sample of 18 patients in each group was required.

A total of 392 adults with asthma (172 women and 220 men; mean age, 39.1 \pm 8.3 years) were enrolled at the respiratory clinic of Binhai County People's Hospital (Jiangsu, China) between August 2017 and November 2018. No patients had received oral glucocorticoids for $>1$ month before enrollment in the present study. Patients who had a history of infection, who had received immunotherapy or who had smoked in the previous month were excluded.
All 392 asthmatic patients received oral prednisolone (40 mg/1.73 m²/d; Wockhardt, Ltd.) for 14 days. The clinical response of patients to corticosteroid therapy was measured with a PC-based spirometer (WinspiroPRO; Medical International Research). Patients with asthma were defined as SR if they experienced $<10 \%$ improvement, or as SS if they experienced $\geq 10 \%$ improvement in baseline forced expiratory volume (FEV) in $1 \mathrm{sec}$ after a 14-day course of oral prednisolone (20). In total, 20 patients were diagnosed with SR asthma and 372 patients were diagnosed with SS asthma. According to the SR group, 34 sex and age-matched SS asthma controls were selected from 372 hormone therapy sensitive patients. Patient characteristics are presented in Table I.

Peripheral blood sample preparation. A total of $20 \mathrm{ml}$ peripheral venous blood was collected from each patient. Then, $1 \mathrm{ml}$ was collected into a tube containing heparin sodium (10 IU/ml; Sigma-Aldrich; Merck KGaA) for iTr35 cell and intracellular p-p38 MAPK flow cytometric analysis within $24 \mathrm{~h}$, and another $1 \mathrm{ml}$ was centrifuged at room temperature for $10 \mathrm{~min}$ at $840 \mathrm{x} \mathrm{g}$ to prepare serum, which was stored at $-80^{\circ} \mathrm{C}$ for later cytokine IL-35 determination. The remaining $18 \mathrm{ml}$ was used for monocyte isolation and culture.

Flow cytometric detection of iTr35 cells. For iTr35 cell analysis, $100 \mu \mathrm{l}$ venous blood was activated with ionomycin $(1 \mu \mathrm{g} / \mathrm{ml})$, monensin $(1 \mu \mathrm{g} / \mathrm{ml})$ and phorbol-12-myristate-13-acetate (50 ng/ml; all from Sigma-Aldrich; Merck KGaA) for $5 \mathrm{~h}$ at $37^{\circ} \mathrm{C}$. After erythrocytes were lysed in fluorescence-activated cell sorting lysing solution (BD Biosciences), the remaining cells were stained with PerCP-cy5.5-conjugated anti-CD4 antibodies (1:10; cat. no. 4291864; ebioscience; Thermo Fisher Scientific, Inc.) for $30 \mathrm{~min}$ at room temperature. Next, cells were fixed and permeabilized using the BD cytofix/cytoperm kit according to the manufacturer's protocol (BD Biosciences), before staining with phycoerythrin-conjugated anti-IL-27 EBI3 (1:10; cat. no 4329546), eFluor 660 labeled anti-IL-12P35 (1:10; cat. no 4323861), and FITC-conjugated anti-forkhead box P3 (Foxp3) antibodies (1:10; cat. no E15373-103) (all from ebioscience; Thermo Fisher Scientific, Inc.) for $20 \mathrm{~min}$ at room temperature. Then, cells were analyzed by a flow cytometer (Becton, Dickinson and Company).

iTr35 cell were identified as follows: i) Forward and side scattering was used to gate lymphocytes; ii) CD4-positive and Foxp3-negative cells were detected in gated lymphocytes; and iii) IL-12P35 and IL-27EBI3 double positive cells were detected in $\mathrm{CD}^{+}{ }^{+}$Fox $33^{-}$lymphocytes. The iTr35 cell percentage was measured as the percentage of CD4 ${ }^{+}$FoxP3-IL-12P35 ${ }^{+} \mathrm{IL}^{-27 \mathrm{EBI}^{+}}{ }^{+}$cells among the CD4 ${ }^{+}$ $\mathrm{T}$ cells.

Isolation and treatment of monocytes. PBMCs were isolated by two-step gradient centrifugation (21). PBMCs were obtained by Ficoll-Hypaque density gradient centrifugation (at room temperature for $20 \mathrm{~min}$ at $800 \mathrm{x} \mathrm{g}$ ) and resuspended in Percoll solution $1(\rho=1.123 \mathrm{~g} / \mathrm{ml})$. Then, the cells were overlaid with Percoll solution $2(\rho=1.064 \mathrm{~g} / \mathrm{ml})$ and Percoll solution 3 $(\rho=1.032 \mathrm{~g} / \mathrm{ml}$; all, Beijing Solarbio Science \& Technology Co., Ltd.) at room temperature for $5 \mathrm{~min}$. Monocytes were 
Table I. Clinical characteristics of patients with asthma.

\begin{tabular}{lcc}
\hline Characteristics & $\begin{array}{c}\text { SR asthma } \\
(\mathrm{n}=20)\end{array}$ & $\begin{array}{c}\text { SS asthma } \\
(\mathrm{n}=34)\end{array}$ \\
\hline Age, years & $37.4 \pm 6.2$ & $38.6 \pm 6.4$ \\
Sex, male/female & $10 / 10$ & $17 / 17$ \\
BMI, $\mathrm{kg} / \mathrm{m}^{2}$ & $27.4 \pm 2.3$ & $27.1 \pm 2.4$ \\
Baseline predicted FEV1\% & $62.5 \pm 5.7^{\mathrm{a}}$ & $73.1 \pm 6.3$ \\
IgE, U/ml & $180.6 \pm 55.2^{\mathrm{a}}$ & $129.6 \pm 43.2$ \\
Change in FEV1\% after & $2.5 \pm 0.9^{\mathrm{a}}$ & $25.6 \pm 8.2$ \\
prednisone burst & & \\
\hline
\end{tabular}

${ }^{\mathrm{a}} \mathrm{P}<0.05$ vs. SS asthma. BMI, body mass index; IgE, immunoglobulin E; SS, steroid-sensitive; SR, steroid-resistant; FEV1, forced expiratory volume in $1 \mathrm{sec}$.

obtained from the RPMI/Percoll interface after centrifugation at $1,000 \mathrm{x}$ g for $90 \mathrm{~min}$ at $20^{\circ} \mathrm{C}$. The purity of monocytes was $80-85 \%$ as measured by flow cytometric analysis of the CD14 $4^{+}$ cells as previously described (6). Isolated monocytes were resuspended in RPMI 1640 (Gibco; Thermo Fisher Scientific, Inc.) containing 10\% FBS (Sigma-Aldrich; Merck KGaA) for in vitro culture.

To examine the cellular responses to IL-35 treatment, monocytes were seeded at a density of $5 \times 10^{5}$ cells $/ \mathrm{ml}$ in 24 -well plates (Corning, Inc.) and treated with RPMI 1,640 containing $20 \mathrm{ng} / \mathrm{ml} \mathrm{rIL-35} \mathrm{(PeproTech,} \mathrm{Inc.)} \mathrm{for} 4 \mathrm{~h}$ at $37^{\circ} \mathrm{C}$. This was followed by cell stimulation by $10 \mathrm{nM}$ DEX (Sigma-Aldrich; Merck KGaA), with or without $1 \mathrm{ng} / \mathrm{ml}$ LPS (Sigma-Aldrich; Merck KGaA) for $3 \mathrm{~h}$ at $37^{\circ} \mathrm{C}$. Cells were collected for MKP-1 mRNA reverse transcription-quantitative PCR (RT-qPCR) or chromatin immunoprecipitation (ChIP) assay. The expression level of p-p38 MAPK in $\mathrm{CD}_{14}{ }^{+}$cells was analyzed by flow cytometric analysis.

Corticosteroid sensitivity assay. Monocytes were seeded at a density of $1 \times 10^{4}$ cells/ml in 96-well plates (Corning, Inc.) and pre-incubated with different concentrations of DEX $\left(10^{-11}-10^{-6} \mathrm{M}\right)$ for $1 \mathrm{~h}$ prior to stimulation with $1 \mathrm{ng} / \mathrm{ml}$ LPS at $37^{\circ} \mathrm{C}$. After $24 \mathrm{~h}$ in culture, the cell supernatant was collected via centrifugation at a speed of $800 \mathrm{x} \mathrm{g}$ for $5 \mathrm{~min}$ at room temperature and stored at $-80^{\circ} \mathrm{C}$ for IL- 6 analysis using the Bio-plex 200 suspension array Luminex system (Bio-rad Laboratories, Inc.). Corticosteroid sensitivity was evaluated according to the half-maximal inhibitory concentration of DEX with respect to LPS-induced IL-6 maximal production in monocytes (DEX-IC ${ }_{50}$ ). The percentage of maximal inhibition of IL- 6 by DEX was presented as $E_{\max }$. The values for individual patients were presented as $\log \left(\mathrm{DEX}-\mathrm{IC}_{50}\right)$ and compared among groups.

Cytokine assay. Serum IL-35 and IL-6 concentrations in the culture supernatant were detected via the Luminex 200 platform based on the manufacturer's protocol (Bio-rad, Laboratories, Inc.). Each experiment was performed twice. The minimum detectable levels of cytokines IL-35 and IL-6 in the assay were $0.15 \mathrm{ng} / \mathrm{ml}$ and $1.34 \mathrm{pg} / \mathrm{ml}$, respectively. p-p38 MAPK detection by flow cytometric analysis. For intracellular p-p38 MAPK staining, $100 \mu 1$ heparin-anticoagulated venous blood was stained with phycoerythrin-conjugated anti-CD14 monoclonal antibodies for $20 \mathrm{~min}$ at room temperature (1:10; cat. no 1543861; BD Biosciences). Cell fixation and permeabilization were performed using the $\mathrm{BD}$ cytofix/cytoperm kit according to the manufacturer's protocol (BD Biosciences). Subsequently, the cells were stained with FITC-conjugated anti-p-p38 MAPK monoclonal antibodies for $20 \mathrm{~min}$ at room temperature. (1:10; cat. no 127841; BD Biosciences). Then, the expression levels of p-p38 MAPK in $\mathrm{CD} 14^{+}$cells from patients were analyzed using a FACScaliber instrument (BD Biosciences).

MKP-1 mRNA detection by RT- $q P C R$ analysis. After monocytes were treated with rIL-35 followed by DEX with or without LPS, cells were collected and total RNA was extracted using TRIzol ${ }^{\circledR}$ reagent (Invitrogen; Thermo Fisher Scientific, Inc.). cDNA synthesis was carried out using the cDNA RT kit (Applied Biosystems; Thermo Fisher Scientific, Inc.). The temperature protocol was as follows: $10 \mathrm{~min}$ at $25^{\circ} \mathrm{C}$, followed by $50^{\circ} \mathrm{C}$ for $20 \mathrm{~min}$. Next, qPCR was carried out using the QuantiTect SYBR Green PCR kit (Invitrogen; Thermo Fisher Scientific, Inc.). The thermocycling conditions for PCR were as follows: $95^{\circ} \mathrm{C}$ for $5 \mathrm{~min}$; followed by 40 cycles of $95^{\circ} \mathrm{C}$ for $15 \mathrm{sec}, 55^{\circ} \mathrm{C}$ for $25 \mathrm{sec}, 72^{\circ} \mathrm{C}$ for $30 \mathrm{sec}$ and final extension at $72^{\circ} \mathrm{C}$ for $5 \mathrm{~min}$. The following primer sequences were used: MKP-1 sense, 5'-GTCGGTAGAGAGTCTACGCT-3' and antisense, $5^{\prime}$-TCGTGTGGAACATTCATTC-3'; and $\beta$-actin sense, 5'-TGGCACCCAGCACAATGAA-3' and antisense, 5'-CTA AGTCATAGTCCGCCTAGAAGCA-3'. PCR was performed using the ABI 7500 PCR system (Applied Biosystems; Thermo Fisher Scientific, Inc.). Relative MKP-1 mRNA expression levels were calculated by the $2^{-\Delta \Delta \mathrm{Cq}}$ method and normalized against $\beta$-actin expression levels (22).

ChIP assay. To examine the effect of IL-35 on GR binding to the GRE, a GR-binding site in the MKP-1 gene promoter, a ChIP assay was performed using the ChIP-IT Express kit (Zhonghong Boyuan Biotechnology Co., Ltd.), according to the manufacturer's instructions. Monocytes were pre-incubated with $20 \mathrm{ng} / \mathrm{ml} \mathrm{rIL-35}$ for $4 \mathrm{~h}$ at $37^{\circ} \mathrm{C}$, followed by $10 \mathrm{nM}$ DEX for $3 \mathrm{~h}$ at $37^{\circ} \mathrm{C}$. DNA was precipitated by rabbit polyclonal anti-GR antibodies (1:20; cat. no 172832; Zhonghong Boyuan Biotechnology Co., Ltd.) and measured by RT-qPCR. The primers used to detect MKP-1 promoter were synthesized as described previously (23) using the same protocol as listed above. The quantity of anti-GR antibody-precipitated DNA was calculated after normalization to input DNA.

Statistical analysis. Statistical analyses were performed using GraphPad Prism 7.0 software (GraphPad Software, Inc.). Mann-Whitney U test was used for the skewed data expressed as the median (25-75th percentile). Normally distributed data are presented as the mean \pm SD. Statistical significance was analyzed by Student's t-test or one-way ANOVA followed by Tukey's test. Spearman correlation analysis was used to determine the linear correlation coefficients. $\mathrm{P}<0.05$ was considered to indicated a statistical significance difference. 


\section{Results}

Clinical characteristics of study population. The clinical characteristics of the 20 patients who were hormone therapy resistant and the 34 sex and age-matched patients who were hormone therapy sensitive are presented in Table I.

Patients with SR asthma show lower IL-35 concentration and iTr35 cell proportion. By gating for $\mathrm{CD}^{+} \mathrm{T}$ lymphocytes (Fig. 1A), CD4 ${ }^{+}$FoxP3- $\mathrm{T}$ cells were classified (Fig. 1B) and then the percentage of $i \operatorname{Tr} 35$ cells was analyzed in the peripheral blood (Fig. 1C). The percentage of iTr35 cells was significantly lower in patients with SR asthma (median, $0.83 \%$; range, $0.73-1.24 \%$ ) compared with patients with SS asthma (median, 1.18\%; range, 0.95-1.44\%; Fig. 1D).

In addition, the present study measured the expression levels of IL-35 in serum. The concentration of IL-35 was significantly lower in patients with SR asthma (median, $1.32 \mathrm{ng} / \mathrm{ml}$; range, $0.91-1.59 \mathrm{ng} / \mathrm{ml}$ ) compared with patients with SS asthma (median, $1.63 \mathrm{ng} / \mathrm{ml}$; range, $1.17-1.93 \mathrm{ng} / \mathrm{ml}$; Fig. 1E). Correlation analysis results demonstrated a weak positive correlation between the percentage of iTr35 cells $(\mathrm{r}=0.386 ; \mathrm{P}<0.01$; Fig. $1 \mathrm{~F})$ and IL-35 concentration in all patients with asthma.

IL-35 displays a positive correlation with corticosteroid sensitivity in monocytes from patients with asthma. Monocytes from 34 patients with SS asthma and 20 patients with SR asthma were treated with different concentrations of DEX followed by LPS stimulation for $24 \mathrm{~h}$. A higher $\log \left(\mathrm{DEX}-\mathrm{IC}_{50}\right)$ was found for patients with SR asthma (median, -7.1; range, -6.5- -7.5) compared with patients with SS asthma (median, -8.1; range, -7.7- -8.2; $\mathrm{P}<0.05$; Fig. $2 \mathrm{~A}$ ). In addition, the $\mathrm{E}_{\max }$ value was significantly lower in patients with SR asthma (median, 40.6\%; range, 37.2-41.8\%) compared with patients with SS asthma (median, 60.3\%; range, 51.3-67.1\%; $\mathrm{P}<0.01$; Fig. 2B). Therefore, the present results suggested that monocytes in patients with SR asthma were less sensitive to steroid treatment compared with those from patients with SS asthma.

Correlation analysis results identified that the expression levels of IL-35 showed a weak negative correlation with log (DEX-IC 50 ; $=-0.351 ; \mathrm{P}<0.01$; Fig. $2 \mathrm{C}$ ) and a moderate positive correlation with $\mathrm{E}_{\max }$ value $(\mathrm{r}=0.4501 ; \mathrm{P}<0.01$; Fig. $2 \mathrm{D})$ in all patients with asthma. In addition, the FEV1\% predicted had a moderate negative correlation with $\log \left(\mathrm{DEX}-\mathrm{IC}_{50}\right.$; $\mathrm{r}=-0.4302 ; \mathrm{P}<0.01$; Fig. $2 \mathrm{E})$ and a moderately positive correlation with IL-35 ( $\mathrm{r}=0.4424$; $\mathrm{P}<0.001$; Fig. $2 \mathrm{~F}$ ). Collectively, the present results indicated that the decreased IL-35 expression levels may be involved in the corticosteroid insensitivity of monocytes from all patients with asthma.

IL-35 shows a negative correlation with p-p38 MAPK in CD $14^{+}$monocytes of patients with asthma. The present study analyzed the mean fluorescence intensity (MFI) of p-p38 MAPK (p-p38 MFI) in monocytes by flow cytometry (Fig. 3A). Compared to the level in patients with SS asthma (median, 2.7; range, 1.8-4.0), p-p38 MAPK was significantly increased in $\mathrm{CD}_{14}{ }^{+}$monocytes of patients with SR asthma (median, 12.7; range, 10.4-15.1; $\mathrm{P}<0.01$; Fig. 3B). Furthermore, the concentration of IL-35 showed a weak negative correlation with p-p38
MAPK in all patients with asthma ( $\mathrm{r}=0.352$; $\mathrm{P}<0.01$; Fig. $3 \mathrm{C})$. In addition, there was a strong negative correlation between p-p38 MAPK and FEV1\% ( $r=-0.718 ; \mathrm{P}<0.001$; Fig. 3D). Moreover, p38 phosphorylation was found to be moderately positively correlated with $\log \left(\mathrm{DEX}-\mathrm{IC}_{50}\right)(\mathrm{r}=0.594 ; \mathrm{P}<0.001$; Fig. 3E) and moderately negatively correlated with the $\mathrm{E}_{\max }$ value in patients $(\mathrm{r}=-0.631 ; \mathrm{P}<0.001$; Fig. $3 \mathrm{~F})$. Therefore, the present results suggested that IL-35 may be involved in p38 phosphorylation in monocytes.

IL-35 enhances corticosteroid responses and inhibits p-p38 MAPK activation in monocytes. To examine the effects of IL-35 on corticosteroid responses, monocytes were treated with $20 \mathrm{ng} / \mathrm{ml}$ IL-35 and various concentrations of DEX for $4 \mathrm{~h}$ followed by $1 \mathrm{ng} / \mathrm{ml}$ LPS stimulation for $24 \mathrm{~h}$. The value of $\log \left(\mathrm{DEX}-\mathrm{IC}_{50}\right)$ was decreased $(\mathrm{P}<0.05$; Fig. $4 \mathrm{~A}$ and $\mathrm{B})$, and $\mathrm{E}_{\max }$ values were increased $(\mathrm{P}<0.05$; Fig. $4 \mathrm{C}$ and $\mathrm{D})$ by pretreatment with IL-35 in monocytes from both patients with SS and SR asthma. Thus, IL-35 may improve corticosteroid sensitivity in monocytes from both patient groups.

The present study also assessed the effects of IL-35 on suppression of p-p38 MAPK activation. Monocytes were treated with $20 \mathrm{ng} / \mathrm{ml} \mathrm{IL-35}$ for $4 \mathrm{~h}$ followed by $10 \mathrm{nM}$ DEX, with or without subsequent treatment with $1 \mathrm{ng} / \mathrm{ml}$ of LPS for $24 \mathrm{~h}$. It was found that LPS significantly enhanced the percentage of $\mathrm{p}-\mathrm{p} 38^{+} \mathrm{CD} 14^{+}$cells in monocytes from patients with SS $(\mathrm{P}<0.01)$ and $\mathrm{SR}$ asthma $(\mathrm{P}<0.01 ; \mathrm{n}=14$; Fig. 4E and F). However, DEX treatment significantly reversed the LPS-induced p-p38 MAPK activation in monocytes from patients with $\mathrm{SS}$ asthma $(\mathrm{P}<0.01 ; \mathrm{n}=14)$, but no significant suppression was observed in monocytes from patients with $\mathrm{SR}$ asthma $(\mathrm{P}=0.423 ; \mathrm{n}=14)$. Furthermore, it was demonstrated that IL-35 pretreatment significantly suppressed LPS-induced p-p38 MAPK activation in monocytes from patients with SS $(\mathrm{P}<0.01, \mathrm{n}=14)$ and SR asthma $(\mathrm{P}<0.01 ; \mathrm{n}=14)$. In addition, the inhibition achieved with IL-35 + DEX treatment was significantly higher compared with the inhibitory effect caused by DEX or IL-35 alone in monocytes of patients with SS asthma $(\mathrm{P}<0.01 ; \mathrm{n}=14)$. However, IL-35 + DEX treatment did not further increase the inhibition caused by IL-35 alone in monocytes from patients with SR asthma $(\mathrm{P}=0.442 ; \mathrm{n}=14)$.

IL-35 enhances DEX-induced MKP-1 expression in monocytes. A previous study showed that DEX can suppress LPS-induced p38 MAPK activation in monocytes via MKP-1 (13). To investigate the mRNA expression of MKP-1 in response to IL-35 or IL-35 + DEX treatment, monocytes were pretreated with IL-35 for $4 \mathrm{~h}$ followed by DEX treatment for $3 \mathrm{~h}$. Then, cells were collected to examine the mRNA expression of MKP-1 by RT-qPCR.

Compared to media control treatment, DEX pretreatment significantly increased the expression of MKP-1 mRNA in monocytes from both patients with $\mathrm{SS}(\mathrm{P}<0.01 ; \mathrm{n}=14)$ and $\mathrm{SR}$ asthma $(\mathrm{P}<0.01 ; \mathrm{n}=14)$. Furthermore, IL-35 treatment alone did not significantly increase the MKP-1 mRNA expression level in monocytes from both patients with $\mathrm{SS}(\mathrm{P}=0.576 ; \mathrm{n}=14)$ and SR asthma $(\mathrm{P}=0.881 ; \mathrm{n}=14)$. However, IL-35 co-treatment did significantly increase the DEX-induced upregulation of MKP-1 mRNA expression levels in monocytes from both patients with $\mathrm{SS}(\mathrm{P}<0.01 ; \mathrm{n}=14)$ and $\mathrm{SR}$ asthma $(\mathrm{P}<0.01, \mathrm{n}=14$; 
A

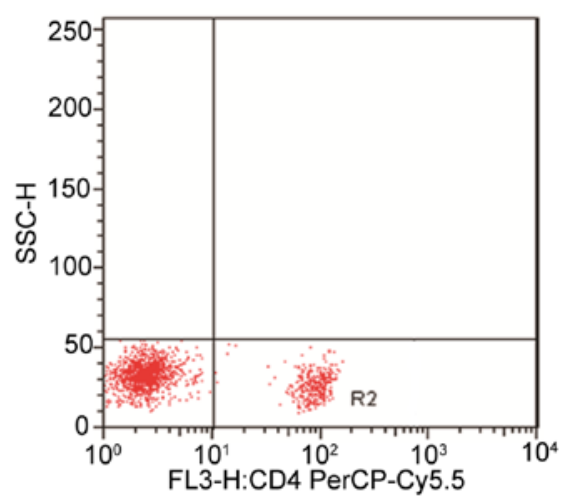

C

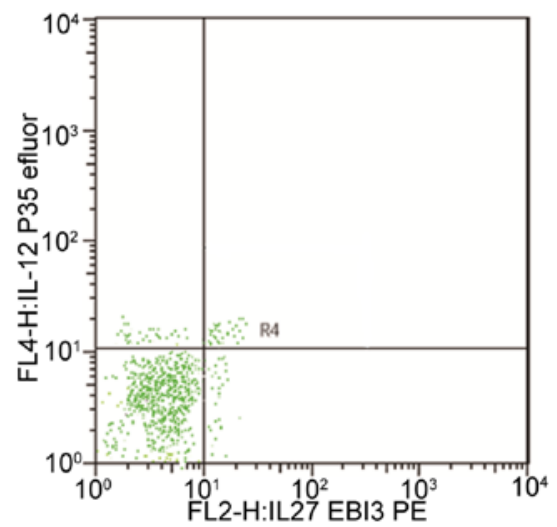

E

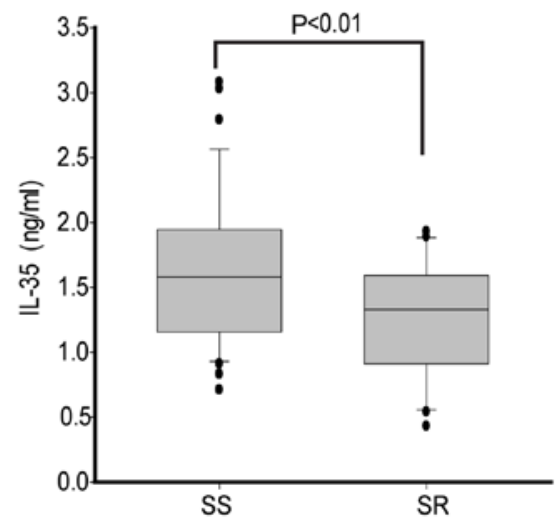

B

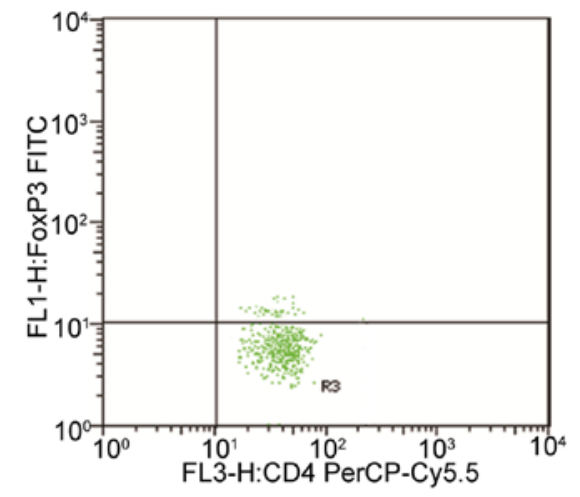

D

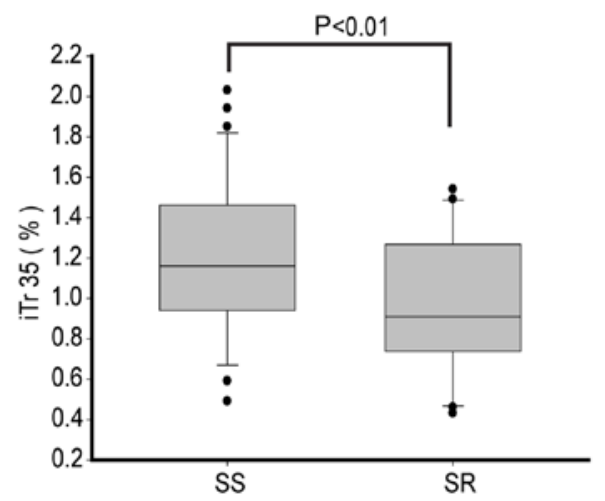

F

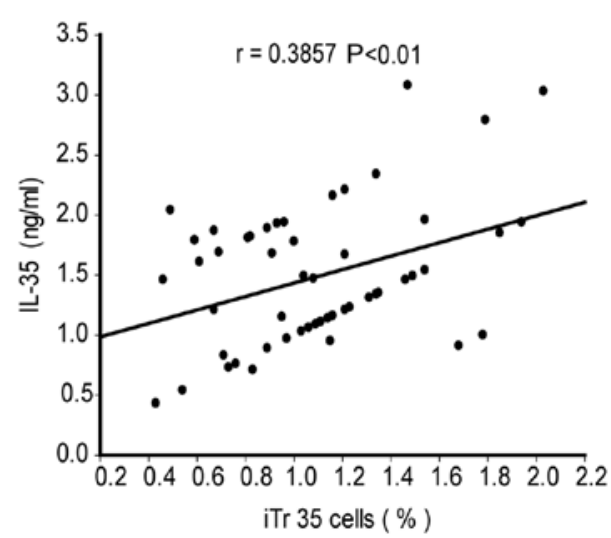

Figure 1. Determining the percentage of iTr35 cells and IL-35 expression levels. iTr35 cell were identified by flow cytometry as follows: R2 contains CD4 ${ }^{+} \mathrm{T}$ cells; R3 contains CD4 ${ }^{+}$FoxP3- T cells; and R4 contains CD4 ${ }^{+}$FoxP3-IL-12P35+IL-27EBI3 ${ }^{+}$cells. (A) Plots of CD4 ${ }^{+}$T cells $(\mathrm{R} 2)$ in gated lymphocytes. (B) Plots of FoxP3- (R3) cells in gated CD4 ${ }^{+}$cells. (C) Plots of IL-27EBI3+ IL-12P35+ (R4) cells in gated CD4 ${ }^{+}$FoxP3- cells. Comparisons of the percentages of (D) iTr35 cells and (E) expression levels of IL-35 in serum between patients with SS or SR asthma. Dots represent outliers and box plots represent median (25-75th percentiles). Statistical significance was analyzed by Mann-Whitney U test. (F) Correlation analysis between the percentage of iTr35 cells and IL-35 concentration in peripheral blood samples from all patients with asthma. The ' $r$ ' denotes the Spearman's correlation coefficient. IL, interleukin; SR, steroid-resistant; SS, steroid-sensitive; FoxP3, forkhead box P3; iTr35, induced regulatory T cells by IL-35; SSC-H, side scatter height; EBI3, Epstein-Barr virus-induced gene 3; $\mathrm{PE}$, phycoerythrin.

Fig. 5A). However, it was found that the mRNA expression level of MKP-1 was significantly higher in monocytes from patients with SS asthma compared with those with SR asthma $(\mathrm{P}<0.01 ; \mathrm{n}=14$; Fig. 5A).

IL-35 enhances GR binding to the GRE in the MKP-1 promoter. GRE, a GR-binding site in the MKP-1 gene promoter, is located in $4.6 \mathrm{~kb}$ upstream of the MKP-1 gene transcriptional start site (Fig. 5B) (23). The present results suggested that IL-35 + DEX differentially upregulated MKP-1 expression levels in monocytes from patients with SS and SR asthma. ChIP assays were performed to further investigate whether this effect was due to differential GR binding to the GRE.

The ChIP assay results found that DEX significantly enhanced GR binding to GRE compared with the media control treatment in monocytes from both patients with SS $(\mathrm{P}<0.01 ; \mathrm{n}=12)$ and SR asthma $(\mathrm{P}<0.01 ; \mathrm{n}=12$; Fig. $5 \mathrm{C})$. However, this GR binding to GRE induced by DEX treatment was significantly higher in monocytes from patients with SS asthma compared with those with $\mathrm{SR}$ asthma $(\mathrm{P}<0.01 ; \mathrm{n}=6$; 
A

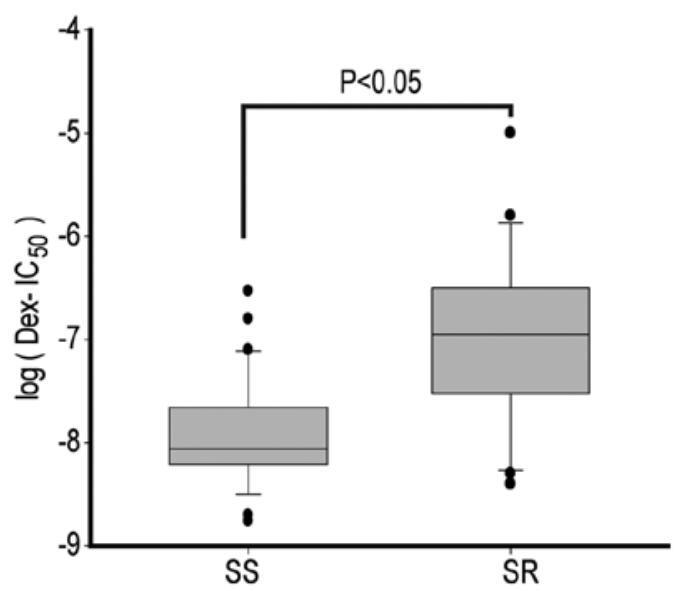

C

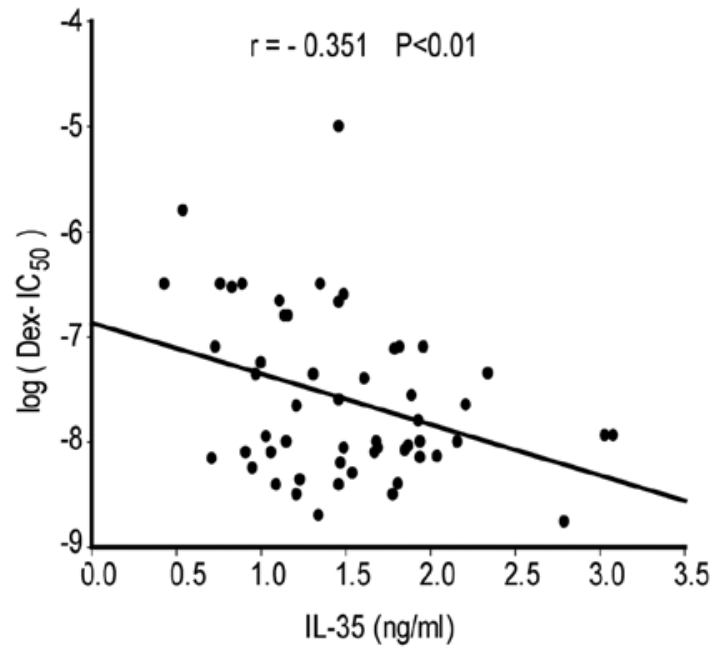

E

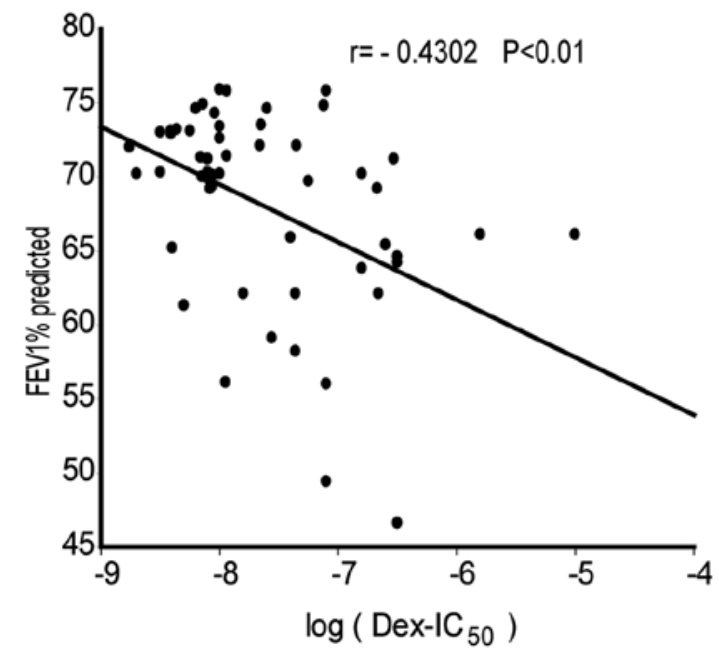

B
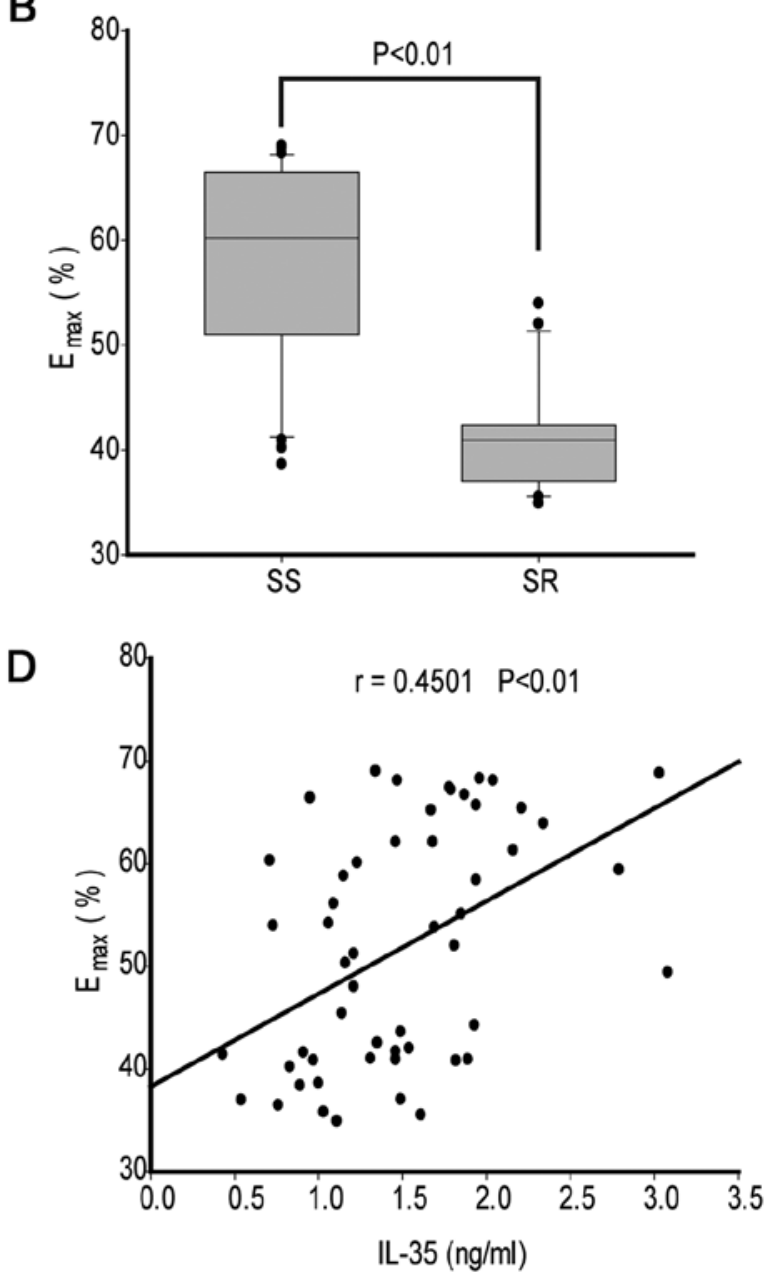

$\mathbf{F}$

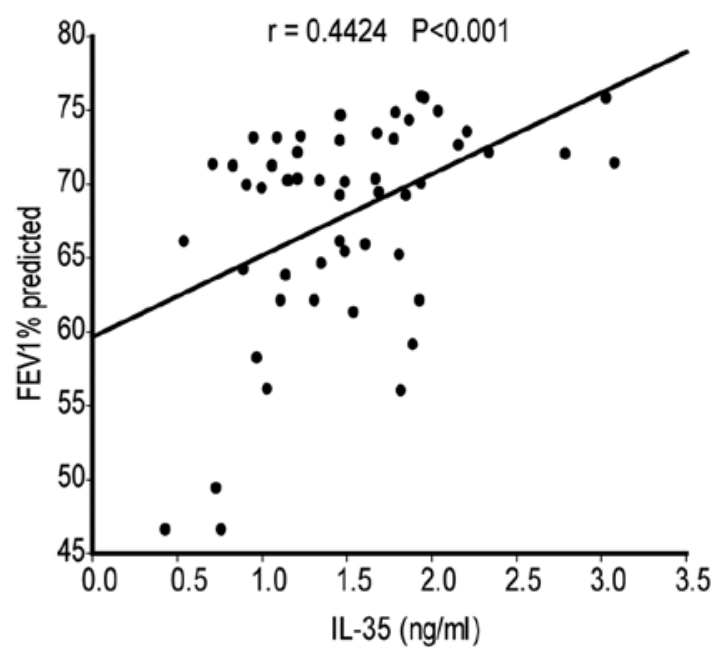

Figure 2. Analysis of corticosteroid sensitivity in peripheral blood monocytes from patients with asthma. Monocytes were preincubated with various concentrations of DEX for $1 \mathrm{~h}$ followed by $1 \mathrm{ng} / \mathrm{ml}$ LPS stimulation for $24 \mathrm{~h}$. Corticosteroid sensitivity was measured as the inhibition rate of IL-6 by DEX. (A) DEX-IC ${ }_{50}$ and (B) $\mathrm{E}_{\max }$ were calculated. Dots represent outliers and box plots represent the median (25-75th percentiles). Statistical significance was analyzed by Mann-Whitney U test. Correlation analysis between the levels of IL-35 with (C) $\log \left(\mathrm{DEX}-\mathrm{IC} \mathrm{F}_{50}\right.$ ) and (D) $\mathrm{E}_{\mathrm{max}}$. Correlation between predicted FEV1\% and (E) $\log \left(\mathrm{DEX}-\mathrm{IC}_{50}\right)$, and $(\mathrm{F}) \mathrm{E}_{\max }$ and FEV1\%. The 'r' denotes the Spearman's correlation coefficient. DEX, dexamethasone; LSP, lipopolysaccharide; $\mathrm{DEX}-\mathrm{IC}_{50}$, half-maximal inhibitory concentration of $\mathrm{DEX}$; $\mathrm{E}_{\max }$, percentage inhibition at maximal concentration; IL, interleukin; FEV1, forced expiratory volume in $1 \mathrm{sec}$; SR, steroid-resistant; SS, steroid-sensitive.

Fig. 5C). Moreover, IL-35 treatment did not enhance GR binding to the GRE in monocytes from either patients with SS $(\mathrm{P}=0.749 ; \mathrm{n}=6)$ or SR asthma $(\mathrm{P}=0.776$; $\mathrm{n}=6$; Fig. 5C).
Furthermore, IL-35 pre-treatment significantly enhanced the DEX-induced increase in GR binding to GRE in monocytes from both patients with $\mathrm{SS}(\mathrm{P}<0.01 ; \mathrm{n}=6)$ and $\mathrm{SR}$ asthma 
A

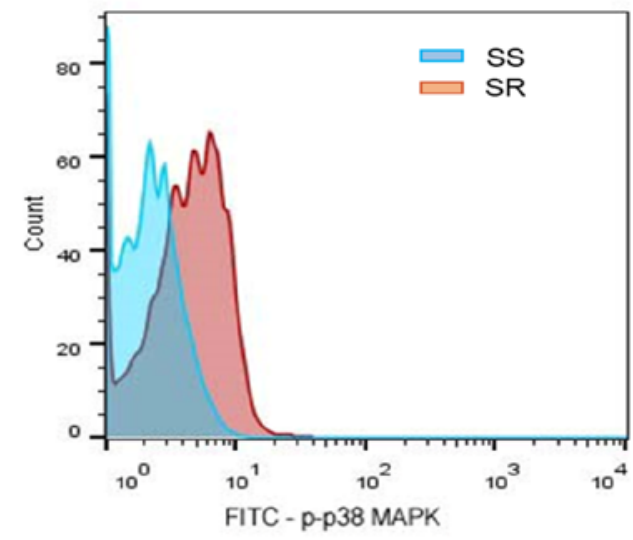

C

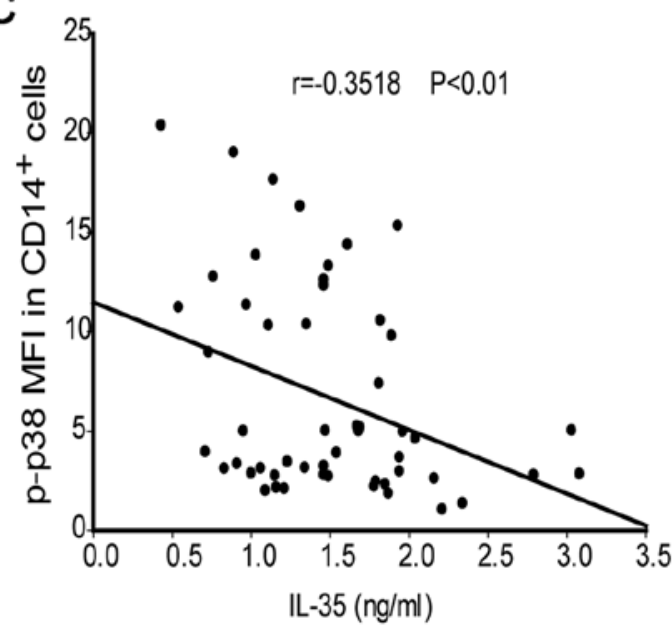

E

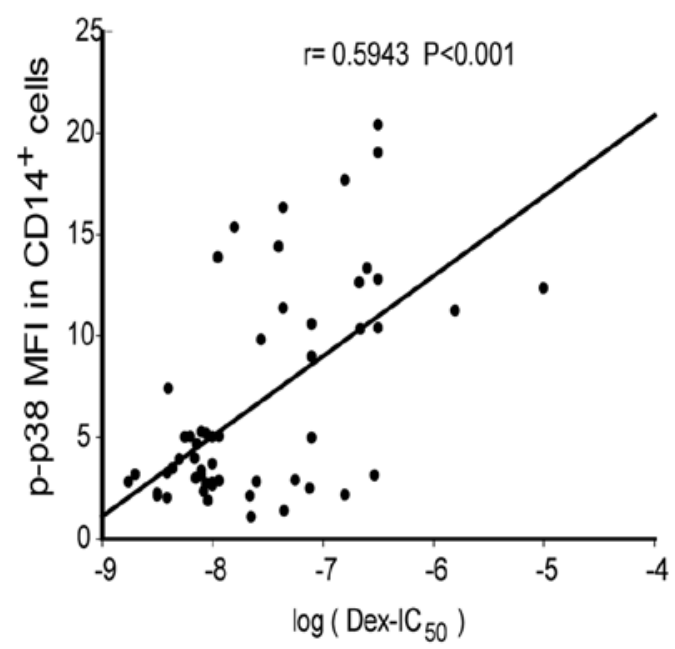

B

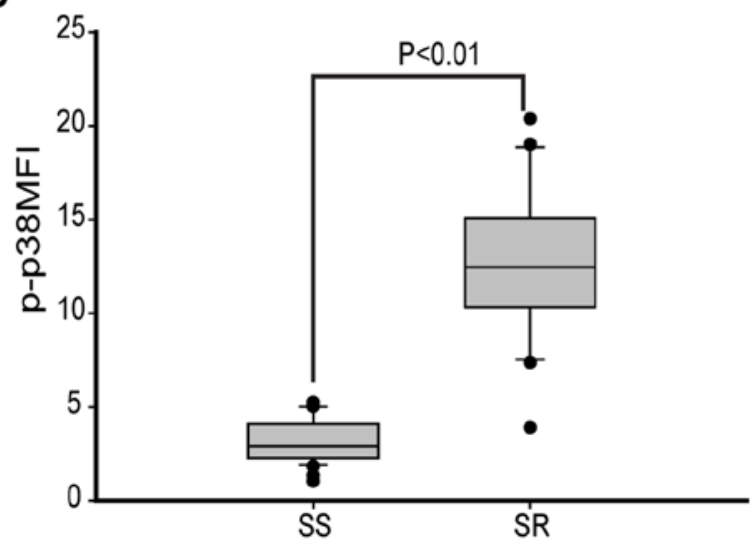

D

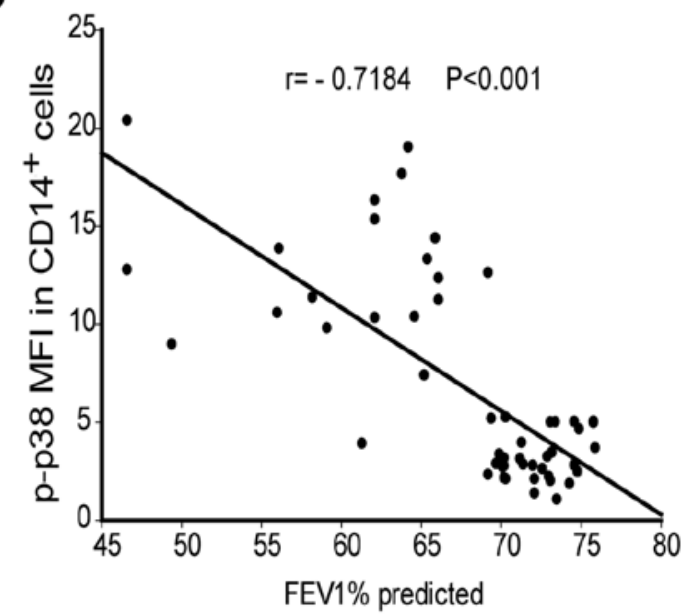

F

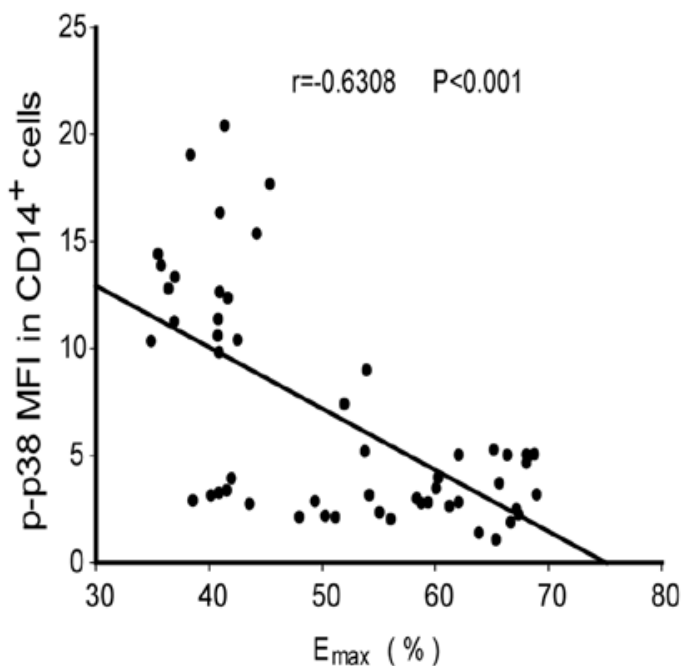

Figure 3. MAPK phosphorylation in CD14+ monocytes from patients with SR or SS asthma. (A) Plots of p-p38 MAPK MFI in gated CD14+ monocytes. (B) p-p38 MAPK MFI in CD14+ monocytes from patients with SR or SS asthma. Correlations between p-p38 MAPK MFI and (C) IL-35 level, (D) predicted FEV1\%, (E) $\log \left(\mathrm{DEX}-\mathrm{IC}_{50}\right)$ and $(\mathrm{F}) \mathrm{E}_{\max }$ were analyzed by Spearman correlation test. Statistical significance was analyzed by Mann-Whitney U test. DEX, dexamethasone; DEX-IC ${ }_{50}$, half-maximal inhibitory concentration of DEX; $\mathrm{E}_{\max }$, percentage inhibition at maximal concentration; IL, interleukin; FEV1, forced expiratory volume in $1 \mathrm{sec}$; SR, steroid-resistant; SS, steroid-sensitive; p-p38 MAPK, phosphorylated P38 mitogen activated kinase; MFI, mean fluorescence intensity.

$(\mathrm{P}<0.01 ; \mathrm{n}=6$; Fig. 5C). However, it was found that in response to IL-35 + DEX, the amount of GR bound to GRE was significantly increased in monocytes from patients with SS asthma compared with those with SR asthma ( $\mathrm{P}<0.01$; $\mathrm{n}=6$; Fig. 5C). Collectively, the present results suggested that there may be a regulatory signaling pathway by which IL-35 enhanced the 
A

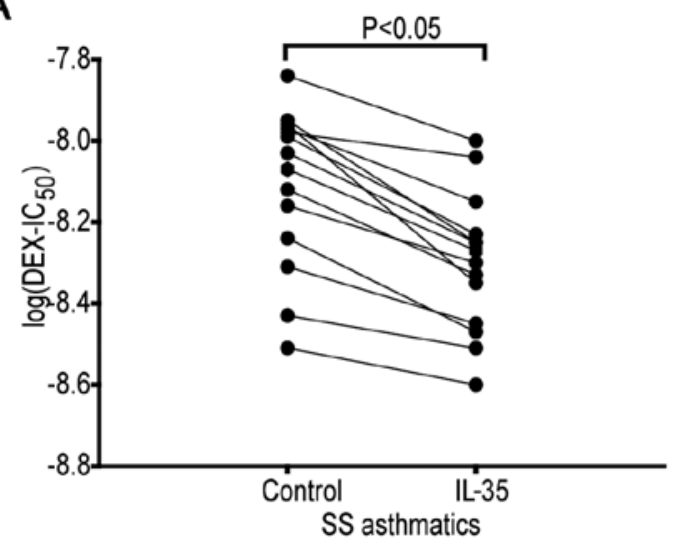

C

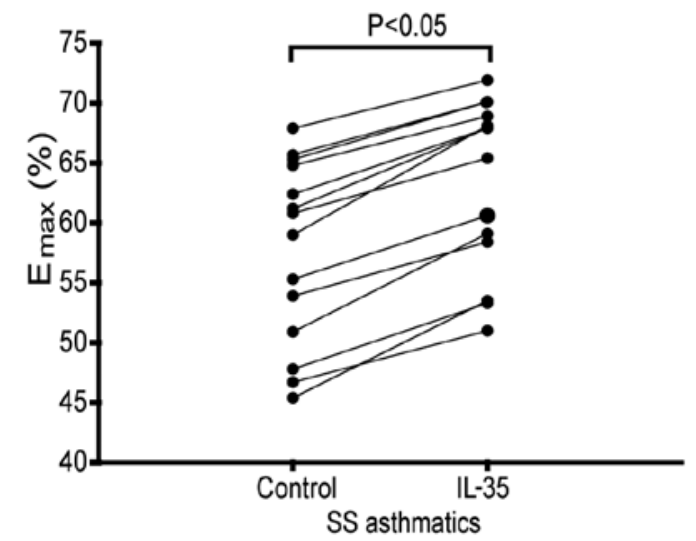

E

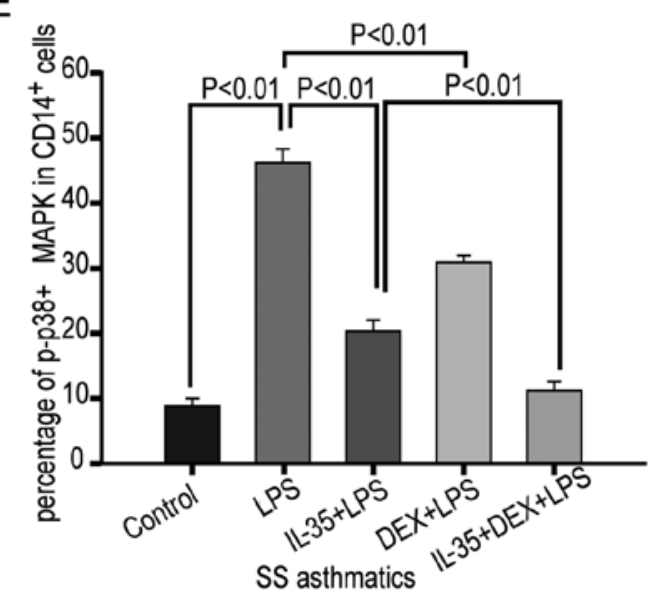

B

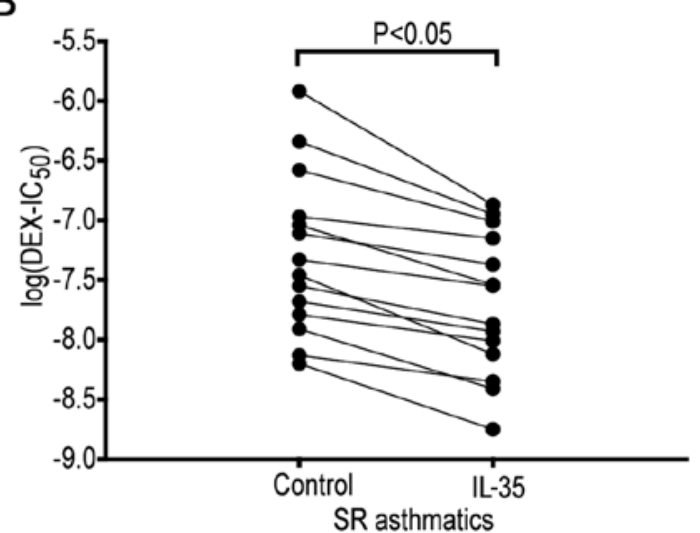

D

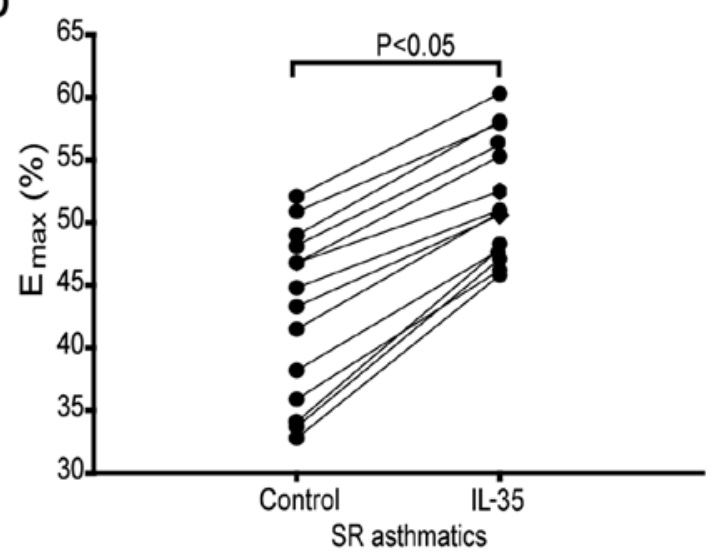

F

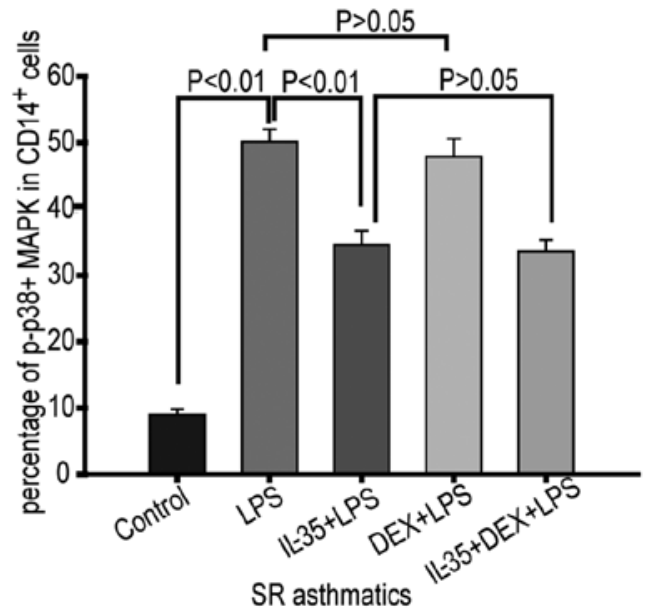

Figure 4. Effect of IL-35 on monocytes from patients with SR or SS asthma. IL-35 decreased the log(DEX-IC $\left.{ }_{50}\right)$ in monocytes from patients with (A) SS (n=14) or (B) SR (n=14) asthma. IL-35 increased $E_{\max }$ in the cells of (C) SS (n=14) and (D) SR ( $\left.=14\right)$ asthma groups. Effects of IL-35 pretreatment (20 ng/ml; 24 h) on LPS- $(1 \mathrm{ng} / \mathrm{ml})$ and DEX- $(10 \mathrm{nM})$ induced p-p38 MAPK expression level in CD14 ${ }^{+}$monocytes from (E) SS and (F) SR asthma groups. DEX, dexamethasone; $\mathrm{DEX}_{-\mathrm{IC}_{50}}$, half-maximal inhibitory concentration of DEX; $\mathrm{E}_{\max }$, percentage inhibition at maximal concentration; IL, interleukin; FEV1\%, forced expiratory volume; SR, steroid-resistant; SS, steroid-sensitive; p-p38 MAPK, phosphorylated P38 mitogen activated kinase.

binding of GR to the GRE and induced MKP-1 expression, thus suppressing LPS-induced p-p38 MAPK activation and enhancing corticosteroid sensitivity in monocytes (Fig. 6).

\section{Discussion}

The present study provided several novel findings. First, the percentage of iTr35 cells and the level of IL-35 in the peripheral blood of patients with SR asthma were significantly lower compared with those in SS asthma. Second, IL-35 enhanced the corticosteroid sensitivity and inhibition of LPS-induced p-p38 MAPK in monocytes treated with DEX from both patients groups. Moreover, it was found that IL-35 may enhance effect of DEX by increasing the MKP-1 mRNA expression level and GR binding to GRE.

The present results, indicating a significant decrease in the percentage of iTr35 cells and expression level of IL-35 in peripheral blood from patients with SR, are consistent with 


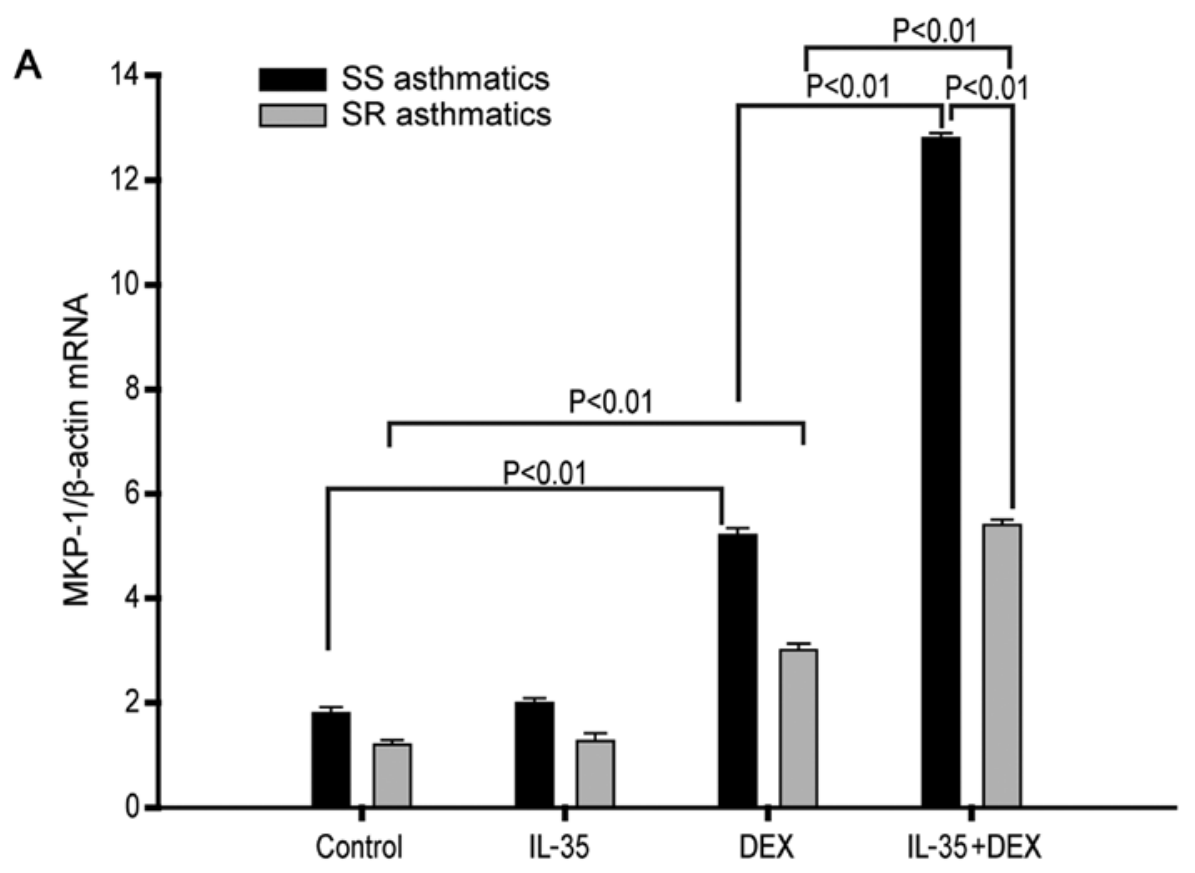

B
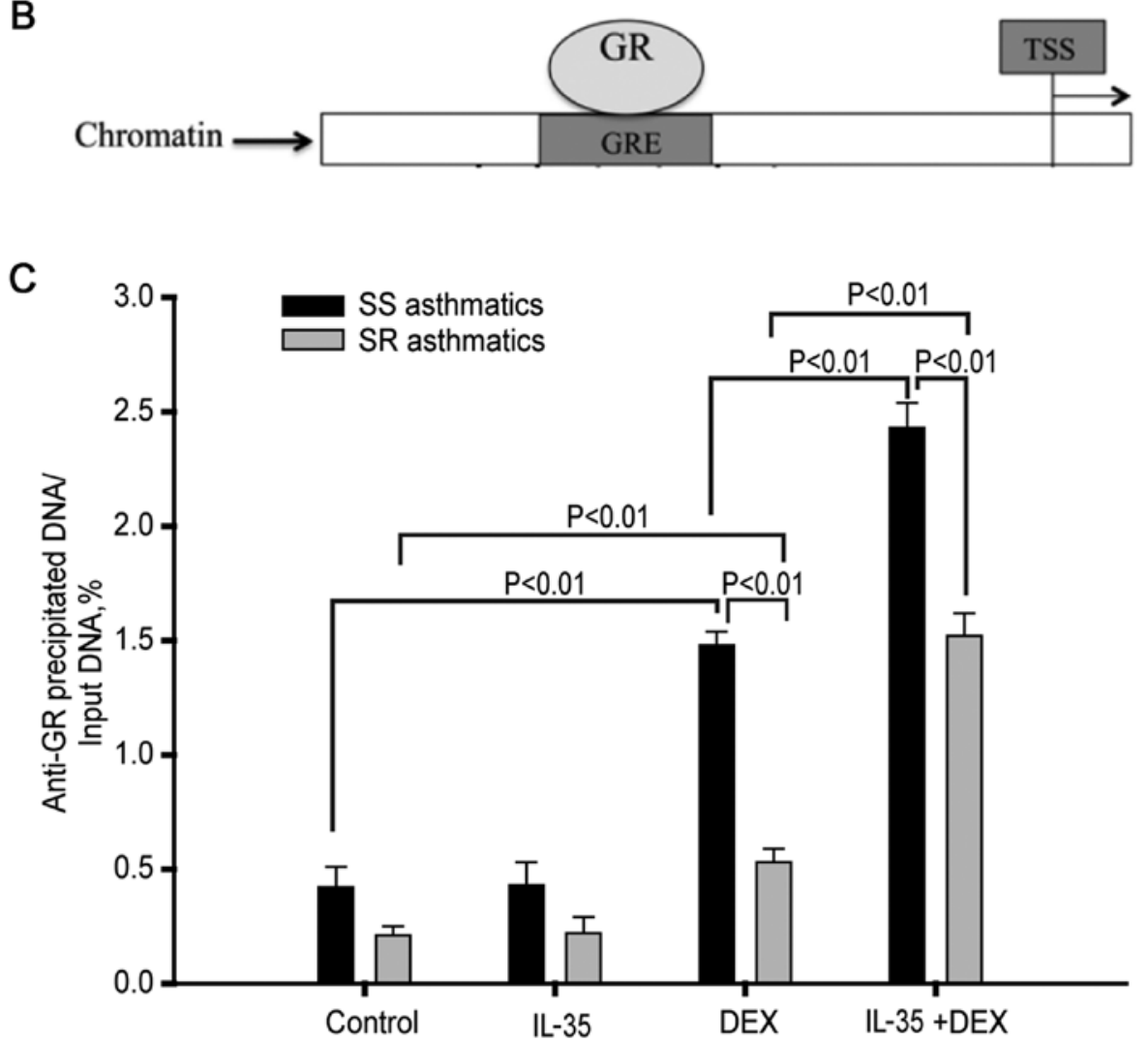

Figure 5. IL-35 enhances DEX-induced MKP-1 expression and recruitment of GR to the GRE in monocytes. (A) MKP-1 mRNA expression level was analyzed by reserve transcription-quantitative PCR. SR, $n=12 ; \mathrm{SS}, \mathrm{n}=12$. (B) Schematic of GR binding to GRE upstream of the TSS of the human MKP-1 gene. (C) Amount of GR bound to GRE as measured by chromatin immunoprecipitation analysis. SR, $n=6 ; \mathrm{SS}, \mathrm{n}=6$. Data are presented as the mean \pm SD. TSS, transcriptional start site; SR, steroid-resistant; SS, steroid-sensitive; IL, interleukin; DEX, dexamethasone; GR, glucocorticoid receptor; GRE, glucocorticoid response element; MKP-1, mitogen-activated protein kinase phosphatase-1.

previous studies showing that decreased IL-35 protein and mRNA expression levels in peripheral blood are significantly related to disease severity, as evidenced by the predicted FEV1\% (24,25). Furthermore, SR asthma is associated with Th1 and Th17-mediated responses, and monocytic or neutrophilic-mediated airway inflammation, most of which are involved in severe asthma, with lower levels of anti-inflammatory cytokines and regulatory immune cells compared with SS asthma (26). In addition, the present study identified a positive correlation between the iTr35 cell percentage and 


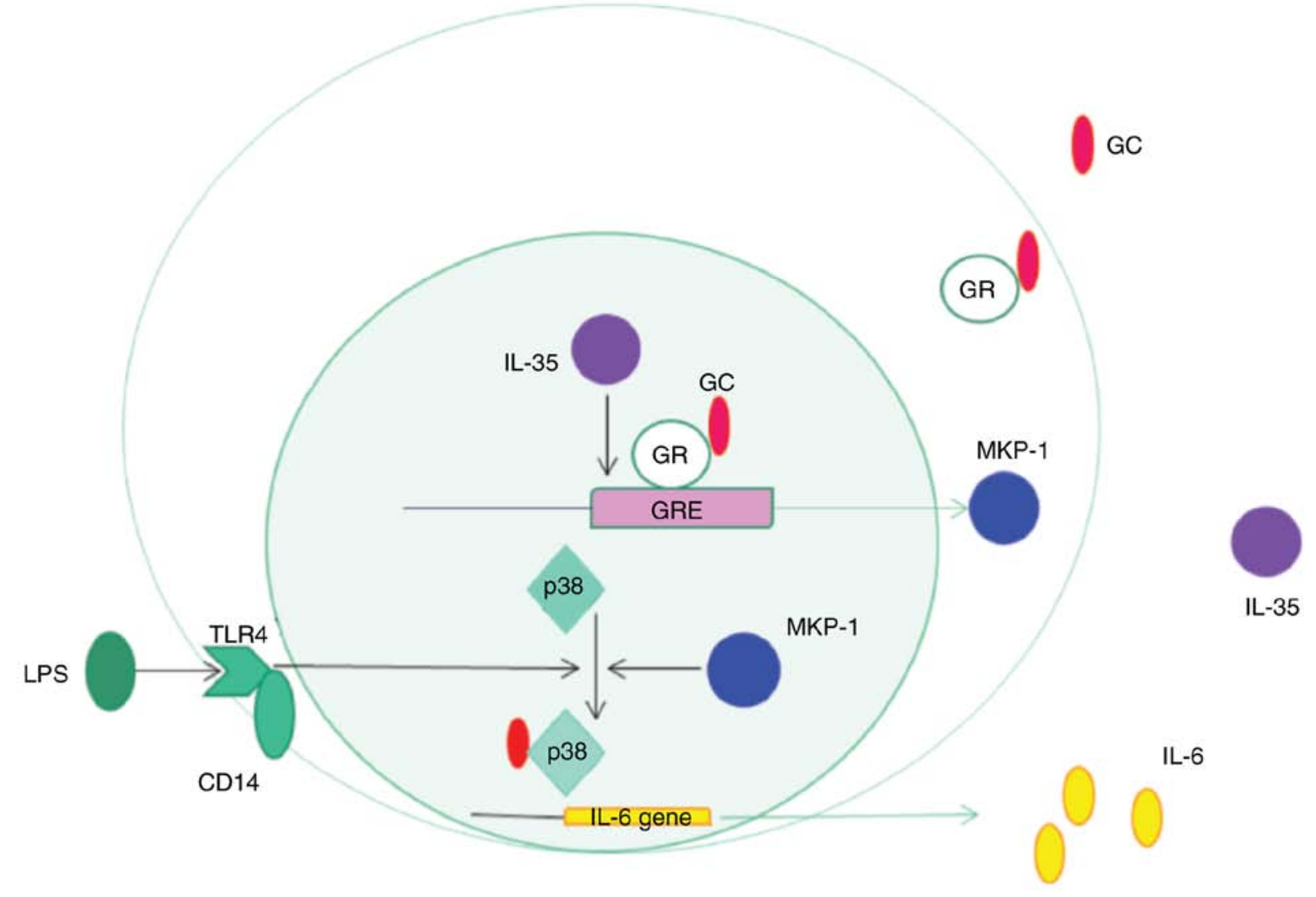

Figure 6. Regulatory model of IL-35 sensitizing monocytes of patients with asthma to the effects of dexamethasone. IL-35 enhanced the binding of GR to the GRE and induced MKP-1 expression, thus suppressing LPS-induced p-p38 MAPK activation and enhancing corticosteroid sensitivity in monocytes. IL, interleukin; LPS, lipopolysaccharide; MKP-1, mitogen-activated protein kinase phosphatase-1; GR, glucocorticoid receptor; GRE, glucocorticoid response element; GC, glucocorticoids; TLR, Toll like receptor.

IL-35 expression level. Therefore, the present results suggested that reductions in IL-35 and iTr35 cells may be involved in the pathogenesis of asthma.

It was found that the expression level of serum IL-35 was negatively correlated with corticosteroid insensitivity in monocytes. In in vitro cell culture, it was demonstrated that IL-35 may improve corticosteroid sensitivity in monocytes from patients with asthma. In addition, IL-35 increased the $\mathrm{E}_{\max }$ of corticosteroids, suggesting that a smaller dose of corticosteroids may be required for asthma treatment. Similarly, it has been demonstrated that vitamin D treatment enhances corticosteroid sensitivity in monocytes from patients with asthma (27). Vitamin D and IL-35 are known for their anti-inflammatory effects in the healthy population and patients with asthma $(17,24,27)$. The present results suggested that anti-inflammatory substances and cytokines may act synergistically with corticosteroid to inhibit the activation of monocytes.

The present study investigated the role of IL-35 in p38 MAPK phosphorylation, which regulates the production of pro-inflammatory cytokines, such as IL-6, IL-8 and tumor necrosis factor- $\alpha$ (28). Activated p38 MAPK in alveolar macrophages of patients with asthma show a positive correlation with the disease severity (12). Activated p38 MAPK in peripheral blood monocytes can be detected by flow cytometric analysis, western blotting or immunohistochemical analysis $(8,27)$. In the present study, flow cytometric detection was chosen due to the small amount of protein in the specimen. It was found that IL-35 was negatively correlated with $\mathrm{p} 38$ phosphorylation in peripheral blood $\mathrm{CD} 14^{+}$monocytes of patients with asthma. In addition, IL-35 pretreatment inhibited LPS-induced p38 phosphorylation in monocytes from both patients with SS and SR asthma. Similarly, using a mouse model of LPS-induced acute inflammation, a previous study demonstrated that IL-35 inhibits endothelial cell activation by suppressing the MAPK-AP1 pathway and attenuating the secretion of proinflammatory cytokines (29).

Glucocorticoid receptor-mediated MKP-1 signaling is a key process in the regulation of steroid resistance and sensitivity (30). The MKP-1 gene promoter region contains binding sites for several transcription factors, such as activator protein 1 (AP-1), AP-2, vitamin D receptor element and GRE (31). In the present study, IL-35 + DEX induced a significantly higher MKP-1 mRNA expression level in patients with SS asthma compared with those with SR asthma, which is consistent with the present p-p38 MAPK data. The ChIP assay results also indicated that IL-35 enhanced binding of GR to GRE in monocytes from patients with SS asthma compared with those with SR asthma, indicating higher MKP-1 gene transcriptional activation in patients with SS asthma.

The present study has limitations that should be considered. First, iTr35 cells can only be detected after activation and permeabilization, and thus they could not be sorted for investigation of their function. Second, the present results 
suggested that IL-35 alone significantly decreased p-p38 MAPK expression in monocytes stimulated by LPS, but did not increase MKP-1 protein expression and GR binding to GRE. Several previous studies have reported that multiple signaling pathways regulate p-p38 MAPK activation at the epigenetic, transcriptional and post-transcriptional levels $(32,33)$. Therefore, IL-35 may inhibit p-p38 MAPK activation via a variety of pathways, thus further research is required. Moreover, the present results indicated that the levels of IL-35 and iTr35 cells in peripheral blood of patients with SR asthma are at a low basal expression, suggesting that modulation of IL-35 and iTr35 levels may be an effective therapeutic approach, such as antigen-specific immunotherapy and intestinal probiotic immunity (34).

In summary, the present results suggested that the percentage of iTr35 cells and the expression level of IL-35 in the peripheral blood of patients with SR asthma were significantly lower compared with those with SS asthma. In addition, it was found that IL-35 had a positive correlation with corticosteroid sensitivity in monocytes from patients with asthma, suggesting potential benefits of IL-35 supplementation with corticosteroids for asthma treatment. Mechanistically, it was demonstrated that IL-35 enhanced the binding of GR to the GRE and induced MKP-1 expression, resulting in suppression of LPS-induced p-p38 MAPK activation and enhanced corticosteroid sensitivity in monocytes from both patient groups.

\section{Acknowledgements}

Not applicable.

\section{Funding}

The current study was supported by The Medical and Health Technology Development Program in Yancheng City, China (grant no. YK2016068).

\section{Availability of data and materials}

All data generated or analyzed during this study are included in this published article.

\section{Authors' contributions}

LQ designed the current study and drafted the manuscript. DX and FX recruited patients and interpreted clinical data. LQ, ML, XW, GL collected, analyzed and interpreted the data. GL designed the clinical study and critically revised the manuscript. All authors read and approved the final manuscript.

\section{Ethics approval and consent to participate}

The present study was carried out under ethical approval from the Ethics Committee of Binhai Hospital (approval no. 2017/05). After detailed explanation, informed consent was provided by all patients.

\section{Patient consent for publication}

Not applicable.

\section{Competing interests}

The authors declared that they have no competing interests.

\section{References}

1. Zervas E, Samitas K, Papaioannou AI, Bakakos P, Loukides S and Gaga M: An algorithmic approach for the treatment of severe uncontrolled asthma. ERJ Open Res 4: 00125-2017, 2018.

2. Fang SB, Zhang HY, Jiang AY, Fan XL, Lin YD, Li CL, Wang C, Meng XC and Fu QL: Human iPSC-MSCs prevent steroid-resistant neutrophilic airway inflammation via modulating Th17 phenotypes. Stem Cell Res Ther 9: 147, 2018.

3. Lea S, Harbron C, Khan N, Booth G, Armstrong J and Singh D: Corticosteroid insensitive alveolar macrophages from asthma patients; synergistic interaction with a $\mathrm{p} 38$ mitogen-activated protein kinase (MAPK) inhibitor. Br J Clin Pharmacol 79: 756-766, 2015.

4. Li JJ, Wang W, Baines KJ, Bowden NA, Hansbro PM, Gibson PG, Kumar RK, Foster PS and Yang M: IL-27/IFN- $\gamma$ induce MyD88-dependent steroid-resistant airway hyperresponsiveness by inhibiting glucocorticoid signaling in macrophages. J Immunol 185: 4401-4409, 2010.

5. Baines KJ, Backer V, Gibson PG, Powel H and Porsbjerg CM: Impaired lung function is associated with systemic inflammation and macrophage activation. Eur Respir J 45: 557-559, 2015.

6. Yuryeva K, Saltykova I, Ogorodova L, Kirillova N, Kulikov E, Korotkaya E, Iakovleva Y, Feoktistov I, Sazonov A and Ryzhov S: Expression of adenosine receptors in monocytes from patients with bronchial asthma. Biochem Biophys Res Commun 464: 1314-1320, 2015

7. Plantinga M, Guilliams M, Vanheerswynghels M, Deswarte K, Branco-Madeira F, Toussaint W, Vanhoutte L, Neyt K, Killeen N, Malissen B, et al: Conventional and monocyte-derived CD11b(+) dendritic cells initiate and Maintain T helper 2cell-mediated immunity to house dust mite allergen. Immunity $38: 322-335$, 2013.

8. Li LB, Leung DY and Goleva E: Activated p38 MAPK in peripheral blood monocytes of steroid resistant asthmatic patients. PLoS One 10: e0141909, 2015.

9. Nixon M, Andrew R and Chapman KE: It takes two to tango: Dimerisation of glucocorticoid receptor and its anti-inflammatory functions. Steroids 78: 59-68, 2013.

10. Kassel O, Sancono A, Krätzschmar J, Kreft B, Stassen M and Cato AC: Glucocorticoids inhibit MAP kinase via increased expression and decreased degradation of MKP-1. EMBO J 20: 7108-7116, 2001.

11. Owens DM and Keyse SM: Differential regulation of MAP kinase signalling by dual-specificity protein phosphatases. Oncogene 26: 3203-3213, 2007.

12. Bhavsar P, Khorasani N, Hew M, Johnson M and Chung KF: Effect of p38 MAPK Inhibition on corticosteroid suppression of cytokine release in severe asthma. Eur Respir J 35: 750-756, 2010.

13. Mercado N, Hakim A, Kobayashi Y, Meah S, Usmani OS, Chung KF, Barnes PJ and Ito K: Restoration of corticosteroid sensitivity by p38 mitogen activated protein kinase inhibition in peripheral blood mononuclear cells from severe asthma. PLoS One 7: e41582, 2012.

14. Ma Y, Chen L, Xie G, Zhou Y, Yue C, Yuan X, Zheng Y, Wang W, Deng L and Shen L: Elevated level of interleukin-35 in colorectal cancer induces conversion of $\mathrm{T}$ cells into $\mathrm{i} \operatorname{Tr} 35$ by activating STAT1/STAT3. Oncotarget 7: 73003-73015, 2016.

15. Whitehead GS, Wilson RH, Nakano K, Burch LH, Nakano H and Cook DN: IL-35 production by inducible costimulator (ICOS)-positive regulatory $\mathrm{T}$ cells reverses established IL-17-dependent allergic airways disease. J Allergy Clin Immunol 129: 207-215.e1-e5, 2012.

16. Zhao H, Liao XL and Kang Y: Tregs: Where we are and what comes next? Front Immunol 8: 1578, 2017.

17. Li Y, Pan X, Peng X, Li S, Zhou Y, Zheng X and Li M: Adenovirus-mediated interleukin-35 gene transfer suppresses allergic airway inflammation in a murine model of asthma. Inflamm Res 64: 767-774, 2015.

18. Dong J, Wong CK, Cai Z, Jiao D, Chu M and Lam CW: Amelioration of allergic airway inflammation in mice by regulatory IL-35 through dampening inflammatory dendritic cells. Allergy 70: 921-932, 2015. 
19. Collison LW, Chaturvedi V, Henderson AL, Giacomin PR, Guy C, Bankoti J, Finkelstein D, Forbes K, Workman CJ, Brown SA, et al: IL-35-mediated induction of a potent regulatory T cell population. Nat Immunol 11: 1093-1101, 2010.

20. Jiang $H$, Chi $X$, Zhang $X$ and Wang J: Increased serum VDBP as a risk predictor for steroid resistance in asthma patients. Respir Med 114: 111-116, 2016.

21. De Almeida MC, Silva AC, Barral A and Barral Netto M: A simple method for human peripheral blood monocyte isolation. Mem Inst Oswaldo Cruz 95: 221-223, 2000.

22. Livak KJ and Schmittgen TD: Analysis of relative gene expression data using real-time quantitative PCR and the 2(-Delta Delta C(T)) method. Methods 25: 402-408, 2001.

23. Tchen CR, Martins JR, Paktiawal N, Perelli R, Saklatvala J and Clark AR: Glucocorticoid regulation of mouse and human dual specificity phosphatase 1 (DUSP1) genes: Unusual cis-acting elements and unexpected evolutionary divergence. J Biol Chem 285: 2642-2652, 2010.

24. Ma Y, Liu X, Wei Z, Wang X, Xu D, Dai S, Li Y, Gao M, Ji C, Guo C, et al: The expression of a novel anti-inflammatory cytokine IL-35 and its possible significance in childhood asthma. Immunol Lett 162: 11-17, 2014.

25. Wang W, Li P, Chen YF and Yang J: A potential immunopathogenic role for reduced IL-35 expression in allergic asthma. J Asthma 52: 763-771, 2015.

26. Kim RY, Pinkerton JW, Essilfie AT, Robertson AAB, Baines KJ, Brown AC, Mayall JR, Ali MK, Starkey MR, Hansbro NG, et al: Role for NLRP3 inflammasome-mediated, IL-1 $\beta$-dependent responses in severe, steroid-resistant asthma. Am J Respir Crit Care Med 196: 283-297, 2017.

27. Zhang Y, Leung DYM and Goleva E: Anti-inflammatory and corticosteroid-enhancing actions of vitamin D in monocytes of patients with steroid-resistant and those with steroid-sensitive asthma. J Allergy Clin Immunol 133: 1744-1752.e1, 2014.
28. Lee HJ, Ko HJ, Song DK and Jung YJ: Lysophosphatidylcholine promotes phagosome maturation and regulates inflammatory mediator production through the protein kinase a-phosphatidylinositol 3 kinase-p38 mitogen-activated protein kinase signaling pathway during mycobacterium tuberculosis infection in mouse macrophages. Front Immunol 9: 920, 2018

29. Sha X, Meng S, Li X, Xi H, Maddaloni M, Pascual DW, Shan H, Jiang X, Wang $H$ and Yang XF: Interleukin-35 inhibits endothelial cell activation by suppressing MAPK-AP-1 pathway. J Biol Chem 290: 19307-19318, 2015.

30. Ramamoorthy S and Cidlowski JA: Exploring the molecular mechanisms of glucocorticoid receptor action from sensitivity to resistance. Endocr Dev 24: 41-56, 2013.

31. Moosavi SM, Prabhala P and Ammit AJ: Role and regulation of MKP-1 in airway inflammation. Respir Res 18: 154, 2017.

32. Xie SJ, Li JH, Chen HF, Tan YY, Liu SR, Zhang Y, Xu H, Yang JH, Liu S, Zheng LL, et al: Inhibition of the JNK/MAPK signaling pathway by myogenesis-associated miRNAs is required for skeletal muscle development. Cell Death Differ 25: 1581-1597, 2018

33. Wang ZK, Dou M, Liu FJ, Jiang P, Ye SL, Ma L, Cao HJ, Du X, Sun P, Su N, et al: GDF11 induces differentiation and apoptosis and inhibits migration of C17.2 neural stem cells via modulating MAPK signaling pathway. PeerJ 6: e5524, 2018.

34. Zhao ST and Wang CZ: Regulatory T cells and asthma. J Zhejiang Univ Sci B 19: 663-673, 2018.

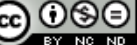

This work is licensed under a Creative Commons Attribution-NonCommercial-NoDerivatives 4.0 International (CC BY-NC-ND 4.0) License. 